\title{
SOME OBSERVATIONS ON UMBILICAL HERNIA IN INFANTS
}

\author{
BY \\ GRACE E. WOODS \\ From the Department of Child Health, University of Bristol
}

(RECEIVED FOR PUBLICATION JULY 20, 1953)

The common condition of infantile umbilical hernia may cause considerable concern among mothers, and there still seems to be some diversity of opinion concerning appropriate treatment. It is probable that the condition is present in one baby in six.

In this paper I have considered 283 infants with umbilical hernia. The time of the first appearance of the hernia has been noted and particular attention has been given to the study of treatment and general prognosis.

\section{Historical}

The condition of the umbilical cord at birth and the umbilicus during infancy has aroused the interest of medical authors down the centuries. Celsus (1st century A.D.) describes an operation by 'ligature' for umbilical hernia at 7 to 14 years. Soranus (A.D. 98-117) suggests that 'it is better to double the cord over and roll it in a little bit of wool and then lay it gently against the middle of the navel, for perchance by the pressure of its weight the part will be moulded to a better shaped depression'.

Widal de Cassis (1848) first described the umbilical fascia as immediately superficial to the parietal peritoneum and posterior to the linea alba and derived from the transversalis fascia.

Richet (1856) considered the fibrous make-up of the umbilical ring and demonstrated that the umbilical ring cannot be closed by direct muscular action but in early infancy it is reinforced by elastic fibres from the obliterated umbilical arteries and takes on the nature of a sphincter. Richet also described an umbilical canal, and he postulates three main types of umbilical hernia-the congenital, the infantile and the adult hernia.

Levadoux (1907) (as quoted at length by Allen) noted the variations in the umbilical fascia and in its disposition, and of the remnants of the umbilical arteries and veins and of the urachus. He concluded that the local fibrous tissue does not reach its full development until after puberty.

More recently Gorelow (1934), on the evidence of 300 dissections, agrees with Richet concerning the identity of an umbilical fascia and umbilical canal.

No case of strangulation of an infantile umbilical hernia has been recorded, and Erichsen (1884) declares that 'these small umbilical herniae are never strangulated and consequently never cause death, yet it is very rare to see one in a child of ten years of age, though in infants we meet them by the score'. Nearly all writers have advocated strapping or a truss or some other restrictive appliance. Opinion on operation has varied if the hernia has not made a spontaneous cure by three to six months of age (Herzfeld, 1938) or to wait as late as five to seven years (Fèvre and Barcat, 1947).

\section{Embryology}

Wyburn (1939) has shown that the mature umbilical cord contains vestiges of the allantois, the omphalomesenteric duct (yolk sac) and the extraembryonic coelom, and is mainly composed of connective tissue formed from the primitive mesoderm. The abdominal parietes, i.e., the rectus sheath, the linea alba and the fascia of the anterior abdominal wall, are formed from intra-embryonic mesoderm which has its origin as the middle layer of cells in the embryonic plate. Fusion of these two distinct forms of mesoderm is at the embryonic rim which is the future umbilical orifice. Proliferation of lateral connective tissue plates passes from the umbilical cord at this point and is responsible for closure of the umbilical ring. A failure in the normal growth of the dense connective tissue which should ultimately occupy the umbilical ring may contribute to local congenital abnormality. In the greater dis- 
order, exomphalos, the supra- and infra-umbilical portions of the abdominal wall have formed, but the intervening area is covered only by amnion and there is no proper umbilical ring.

'Herniae into the umbilical cord' may be considered to be the contrary type of failure. At birth it is evident that a portion of gut has failed, during embryonic life, to return normally into the abdominal cavity through a narrowed neck. The intestinal wall is usually firmly adherent to the upper rim of the umbilical orifice and the 'hernia' cannot be automatically reduced into the peritoneal cavity.

The commonest type of abnormality is when the umbilical ring does not close. A true hernia presents through the ring within a peritoneal sac. The ultimate closure of the umbilical ring depends upon the proliferation of encircling mesoderm. When this obliterative proliferation is incomplete a patent umbilical ring is the result and herniae through this ring during infancy are under particular consideration in this paper.

\section{Anatomy}

From anatomical descriptions and evidence obtained by dissections on 20 neonates it is possible to give a simple picture of the anatomy. The umbilical region is bounded laterally by the rectus muscles enclosed in their sheaths, posteriorly by the parietal peritoneum and anteriorly by the skin. At the umbilical orifice in the linea alba the fibrous remnants of the umbilical arteries are firmly attached to the lower edge of the orifice. The venous remnants are loosely attached to the superior edge of the orifice but are more firmly attached to the inferior and lateral edges (Fig. 1a). This was noted by
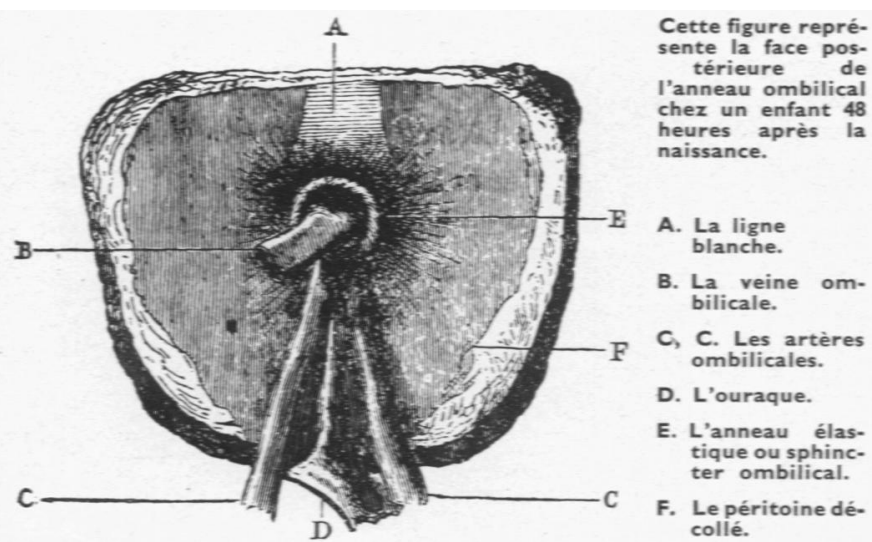

FIG. 1a.-Richet's original drawing (Arch. gen. Med., 1857, 1, 62) showing the loose attachment of the umbilical vein to the walls of the orifice and the much firmer attachment of the arteries and urachus.
Richet (1856). A large amount of embryonic connective tissue fills the lower portion of the umbilicus with a firm layer of tissue which helps to act as an efficient barrier against the development of a hernia (Moschcowitz, 1915).

Dissections have been made on stillborn infants whose umbilical cord was still present. Wharton's jelly was first dissected away. The still patent arteries and vein then lay loose in the dissection and their course through the umbilical orifice to their destinations could be traced. It was then found that the arteries were firmly attached to the lower edge of the umbilical orifice and the corresponding region of the anterior abdominal wall. The umbilical vein had no such attachment and could easily be pulled in and out of the orifice. Whether or not the obliterated vein later became attached to the inferior edge of the umbilical orifice could not be verified by dissection. Thus it is suggested that the umbilicus is weakest at the upper edge of the orifice. Usually hernia presents at the upper edge of the umbilicus.

The umbilical orifice is thus essentially a gap in the linea alba. The size of the gap varies considerably and the recti play no part in its direct formation. By dissection it was found that at the level of the umbilicus the edges of the two recti were separated by 1 to $1.7 \mathrm{~cm}$. The recti in infants are more divaricant supra-umbilically than infraumbilically and 1 to $2 \mathrm{~cm}$. below the orifice the recti muscles are in close apposition at all ages and the linea alba is only a fibrous raphe. This factor, coupled with the additional strength of the inferior edge of the umbilical orifice, creates an effective anatomical barrier against infra-umbilical herniation.

Some divarication of the recti is common in infants and it is possible for wide divarication to be present without a hernia. Alternatively, widely divaricant recti are compatible with a spontaneous disappearance of an umbilical hernia. The tonicity of these muscles is however, of considerable importance. The rectus muscles are attached to the posterior surface of their sheaths and thus to the linea alba by fibrous insertions. Many anatomical studies show that one set of these insertions is always at the level of the umbilicus. Hamilton has noted that 'tendinous fibres develop in fascia in direct response to mechanical stress'. Thus the tone and strength of the rectus muscles undoubtedly affect the strength of the linea alba and the fascial covering of the anterior abdominal wall. 
The umbilical fascia is a direct extension of the transversalis fascia. Gorelow (1934) observed that it was represented by a small number of obliquely running fibres, varying from $0.5 \mathrm{~cm}$. to $6.5 \mathrm{~cm}$. in height. It varied in strength and in position, sometimes lying entirely above the umbilical orifice, sometimes over the orifice, only rarely below the orifice, and always firmly adherent to the peritoneum.

My dissections have confirmed that at the level of the orifice the peritoneum becomes thickened and somewhat toughened and appears to be reinforced by fibrous tissue. Richet considered that this fascia develops in strength during the early months and strengthening the superior edge of the umbilical orifice forms a protection against hernia.

Where there is no appreciable umbilical fascia the peritoneum is not supported and a direct umbilical hernia may form through the umbilical orifice. It is probably this type of hernia which occurs in infants, particularly in premature infants, and spontaneously disappears in the first few months.

Various workers have postulated the existence of an umbilical canal, formed anteriorly by the linea alba, posteriorly by the umbilical fascia and laterally by the medial edges of the rectus sheaths with an entrance up to $3.6 \mathrm{~cm}$. above the site of the obliterated umbilical veins, while in the canal the vein

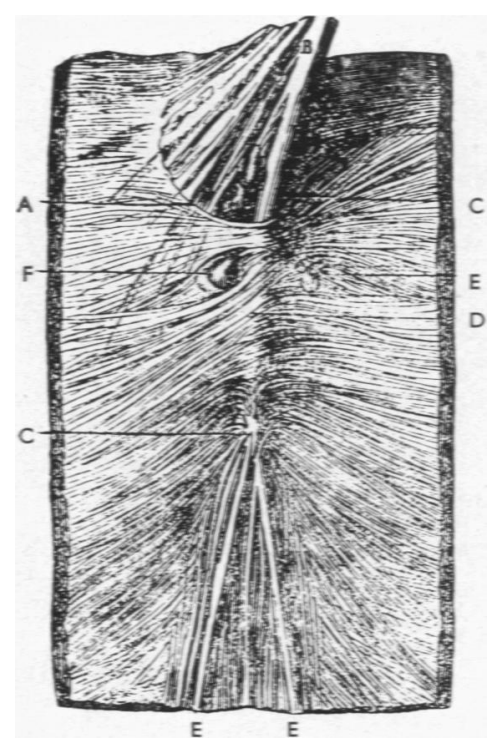

A. L'ouraque et les artères ombilicales soudées ì la cica. trice ombilicale

B. La veine ombilicale.

C, C. Ouverture par laquelle la reine ombilireine ómbire che lans pout tière ou canal ombilical.

D. Fascia ombiliclis, dont les fibres ferment en arrière $b$ couttière ombilicale.

E, F. Hernies graisseuses s'echap pant ì travers des érillures bilicalis.

FKG. 1b.-Richet's original drawing (Arch. gén. Med., 1856, 2, 648) showing the posterior surface of the anterior abdominal wall after the peritoneum has been removed revealing the umbilical canal.

is loosely surrounded by adipose tissue. Richet's original drawings are shown in Figs. $1 b$ and $1 c$.

The umbilical canal, like the inguinal canal, traverses obliquely the abdominal parietes from the peritoneum to the skin surfaces and both have a similar posterior surface of transversalis fascia and peritoneum. It is suggested that herniation down this canal leads to the adult type of umbilical hernia.

It appears that there are two main types of umbilical hernia. A direct umbilical hernia can form through the umbilical orifice when there is an absence or weakness of fascial strengthening. The hernia tends to 'point' at the superior edge of the umbilical orifice as this area is less strengthened by fibrous tissue. This may be the common type of umbilical hernia seen in infants. It is not affected by the presence or absence of divarication of the recti. The hernia tends to be cured spontaneously when the fascia of the abdominal wall has increased in strength. A fairly wide umbilical orifice does not necessarily mean the presence of a hernia, and a hernia may disappear before the orifice has completely closed.

An oblique umbilical hernia may take place through the umbilical canal in later infancy, childhood or adult life. A portion of omentum or bowel passes down the umbilical canal and presents at the

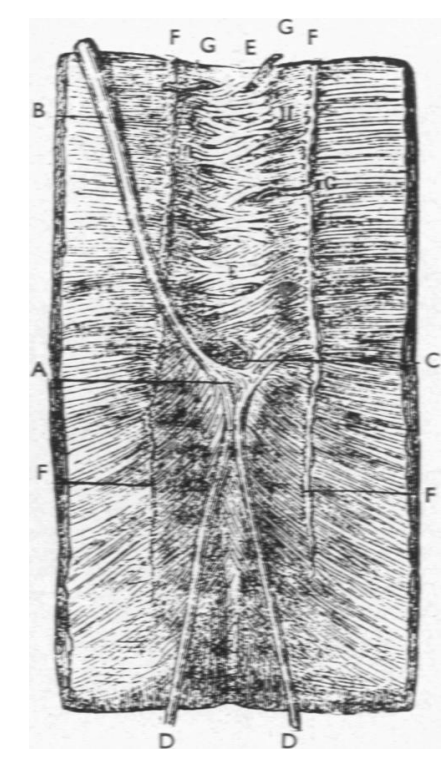

FKG. 1c.-Richet's original drawing (Arch. gen. Med., 1856, 1, 650) showing a similar dissection after the removal of the 
upper edge of the umbilicus. This type is more likely to be persistent and surgical complications might occur.

No essential advances in these aspects of the anatomy of umbilical herniation have been made since Richet's (1856) original publication. His observations on the different anatomical arrangement of infantile and adult hernia closely approximate to the present clinical findings.

\section{Umbilical Hernia in Infancy}

Celsus defines a true hernia as a protrusion of loop or knuckle of an organ or tissue through an abnormal opening'. I have accepted as the criterion of diagnosis the presence of a saccular swelling which protrudes on coughing or crying and which can be reduced by simple pressure through a gap in the umbilicus. By contrast, the absence of any saccular protrusion despite the palpability of a gap at the umbilical orifice would indicate the absence of a true hernia. It should be noted that in some infants at birth there is an unusual length of skin on the umbilical cord which when the cord separates may falsely suggest a hernia (Fig. 2).

My clinical study of umbilical hernia comprises 283 infants in whom the hernia appeared before the age of $2 \frac{1}{2}$ years. Clinical details of the birth, the birth weight, the length of the cord, the day of separation of the cord, the time of appearance of the hernia and the possible related causes have been obtained. Of these infants, 140 were seen at an infant welfare clinic and the remaining 143 were observed in a hospital surgical out-patient department.

Infants who first attended under the age of 3 months at the same infant welfare clinic were taken as controls. With the assistance of health visitors a complete follow-up has been possible, and no control infants have shown any tendency to umbilical hernia.

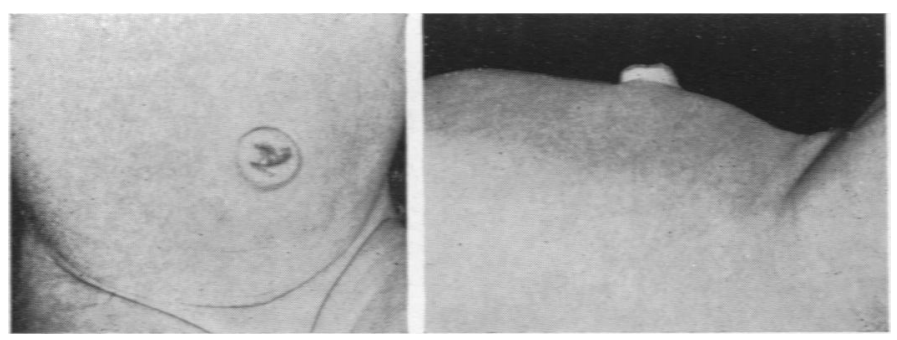

Fig. 2.-Baby aged 31 weeks (10 lb. $12 \mathrm{oz}$. birth weight). The umbilical protrusion is due to an excessive amount of skin only. No umbilical orifice was palpable. The umbilicus was still moist. Strapping was not indicated and would have aggravated the septic condition of the umbilicus.
Frequency

Out of a total of 573 infants who were brought to the infant welfare clinic between December, 1948, and July, 1951, 106 developed an umbilical hernia before the age of 6 months. This is an incidence of 1 in $5 \cdot 4$.

\section{Type of Birth}

Table 1 compares the type of birth in 276 infants with umbilical hernia with 453 controls who were born between December, 1948, and July, 1951, in the same area as the clinic cases, on the basis of information obtainable from hospital and midwife records.

TABLE 1

COMPARISON OF TYPE OF BIRTH IN AFFECTED INFANTS AND CONTROLS

\begin{tabular}{|c|c|c|c|c|c|c|}
\hline \multirow{2}{*}{\multicolumn{3}{|c|}{ Type of Birth }} & \multicolumn{2}{|c|}{ Umbilical Herniae } & \multicolumn{2}{|c|}{ Controls } \\
\hline & & & No. & $\%$ of Total & No. & o of Total \\
\hline \multirow[t]{2}{*}{$\begin{array}{l}\text { Normal birt } \\
\text { Forceps } \\
\text { Breech } \\
\text { Caesarean } \\
\text { Twins }\end{array}$} & $\begin{array}{c}\text { rth } \\
\ldots \\
\cdots \\
\cdots \\
\cdots\end{array}$ & $\begin{array}{l}\cdots \\
\cdots \\
\cdots \\
\cdots\end{array}$ & $\begin{array}{r}244 \\
5 \\
7 \\
5 \\
13\end{array}$ & $\begin{array}{r}88 \cdot 9 \\
1 \cdot 9 \\
2 \cdot 5 \\
1 \cdot 9 \\
4 \cdot 8\end{array}$ & $\begin{array}{r}439 \\
8 \\
3 \\
3 \\
0\end{array}$ & $\begin{array}{l}96 \cdot 9 \\
1.7 \\
0.7 \\
0.7 \\
0.0\end{array}$ \\
\hline & & & 274 & 100 & 453 & 100 \\
\hline
\end{tabular}

These figures show significantly that hernia occurs more frequently in twin births. In fact, all the twins seen in the survey developed umbilical herniae. There is a possible tendency for a higher incidence in breech births.

The birth weights of infants developing umbilical hernia and of controls are shown in Table 2 and Fig. 3.

It will be noted that $2 \cdot 8 \%$ of the controls were under $5 \frac{1}{2} \mathrm{lb}$. at birth. $9.0 \%$ of the affected children were under $5 \frac{1}{2} \mathrm{lb}$. at birth, $5 \cdot 3 \%$ of the controls were over $9 \mathrm{lb}$. at birth and $9.0 \%$ of the affected children were over $9 \mathrm{lb}$. at birth. There is, therefore, evidence that umbilical hernia is more common in premature babies (i.e., $5 \frac{1}{2} \mathrm{lb}$. or less at birth) and a suggestion that the same is true of babies above $9 \mathrm{lb}$. at birth. The incidence in large babies may be due to a larger cord, which may be particularly noticeable in some large babies.

\section{Length of Cord}

The length of the cord at birth was 
TABLE 2

BIRTH WEIGHTS IN AFFECTED INFANTS AND CONTROLS

\begin{tabular}{|c|c|c|c|c|}
\hline \multirow{2}{*}{ Birth Weight (lb.) } & \multicolumn{2}{|c|}{ Herniae } & \multicolumn{2}{|c|}{ Controls in Same Area } \\
\hline & No. & $\%$ & No. & $\%$ \\
\hline 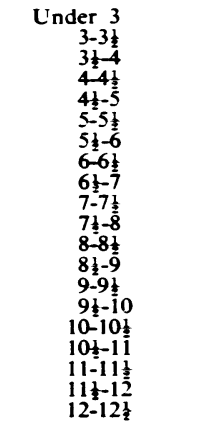 & $\begin{array}{r}0 \\
0 \\
0 \\
4 \\
6 \\
11 \\
24 \\
16 \\
40 \\
51 \\
49 \\
29 \\
15 \\
8 \\
7 \\
7 \\
0 \\
1 \\
0 \\
1\end{array}$ & $\begin{array}{r}0 \cdot 0 \\
0 \cdot 0 \\
0 \cdot 0 \\
1 \cdot 5 \\
2 \cdot 2 \\
4 \cdot 1 \\
9 \cdot 0 \\
6 \cdot 0 \\
14 \cdot 8 \\
19 \cdot 0 \\
18 \cdot 3 \\
10 \cdot 7 \\
5 \cdot 6 \\
3 \cdot 0 \\
2 \cdot 5 \\
2 \cdot 5 \\
0 \cdot 0 \\
0 \cdot 4 \\
0 \cdot 0 \\
0 \cdot 4\end{array}$ & $\begin{array}{r}0 \\
2 \\
1 \\
0 \\
2 \\
8 \\
22 \\
51 \\
62 \\
77 \\
86 \\
90 \\
44 \\
12 \\
8 \\
3 \\
1 \\
1 \\
0 \\
0\end{array}$ & $\begin{array}{c}0 \cdot 0 \\
0 \cdot 4 \\
0 \cdot 2 \\
0 \cdot 0 \\
0 \cdot 4 \\
1 \cdot 7 \\
4 \cdot 7 \\
10 \cdot 9 \\
13 \cdot 2 \\
16 \cdot 4 \\
18 \cdot 3 \\
19 \cdot 1 \\
9 \cdot 4 \\
2 \cdot 6 \\
1 \cdot 7 \\
0 \cdot 6 \\
0 \cdot 2 \\
0 \cdot 2 \\
0 \cdot 0 \\
0 \cdot 0\end{array}$ \\
\hline $12-12 \frac{1}{2}$ & 268 & 100 & 470 & 100 \\
\hline
\end{tabular}

obtained wherever possible and compared with the controls (Table 3 ).

I am indebted to Dr. G. Herdan for the following comment on these figures:

TABLE 3

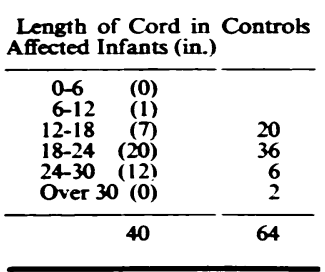

'Although numbers in Table 3 are not sufficient for statistical testing of any difference that may exist in the two distributions, yet mere inspection shows distributions so strikingly different that the influence of the length of the cord upon the investigated phenomenon seems at least likely.'

I have no evidence to explain a possible relationship between length of the cord and the

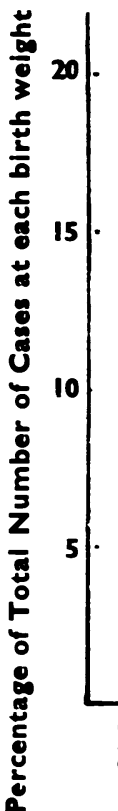

occurrence of umbilical hernia, nor have I evidence that traction on the cord during birth contributes to a hernia, although a possibility is suggested by the somewhat higher incidence in breech births.

Day of Separation of Cord

TABLE 4 DAY OF SEPARATION OF THE CORD

\begin{tabular}{|c|c|c|}
\hline Day & Affected Children & Controls \\
\hline $\begin{array}{l}\text { 3rd } \\
4 \text { th } \\
5 \text { th } \\
6 \text { th } \\
7 \text { th } \\
8 \text { th } \\
9 \text { th } \\
10 \text { th } \\
11 \text { th } \\
12 \text { th } \\
13 \text { th } \\
14 \text { th } \\
15 \text { th }\end{array}$ & 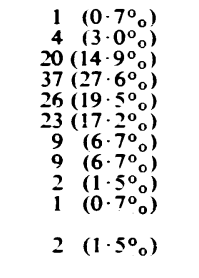 & 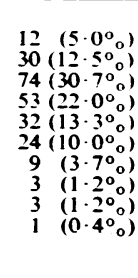 \\
\hline & $134\left(100_{0}^{\circ}\right)$ & $241\left(100^{\circ} 0\right)$ \\
\hline
\end{tabular}

Nosignificant difference is noted between the hernia cases and the controls and no evidence is obtained that the type of treatment of the cord after birth has an influence on the later development of a hernia.

Of the various modes of dressing the cord, it was noted that of 43 infants treated by a method in which no dressing or binder is applied but the cord is merely covered with collodion and allowed to drop off, 10 developed herniae, a similar incidence to that in the more orthodox method of treating the cord.

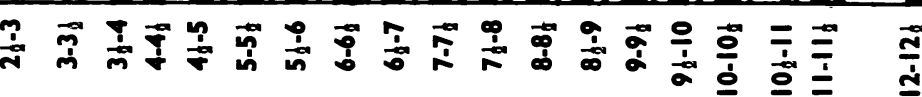

\section{Birth Weight (Ib.)}

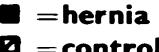


Condition of Umbilicus after Separation of Cord

A common belief is that sepsis of the umbilicus after separation of the cord tends to induce a hernia. The condition of the umbilicus after separation of the cord was carefully recorded in all children who later attended the infant welfare clinic both in those who ultimately developed hernia and in the controls. In the majority of cases the umbilicus became dry within a few days of separation of the cord and no further dressing was required. In some cases minor local bleeding recurred for several weeks. In others the umbilical area became frankly septic with a purulent discharge, the folds of skin around the umbilicus becoming crusted and adherent with pus. In a small number of cases this septic condition led to the formation of a local soft granuloma, which could readily be distinguished from a cord stump which was firm and tough.

Table 5 gives the incidence of five common conditions in the affected children and in the controls.

TABLE 5

INCIDENCE OF COMMON CONDITIONS IN THE AFFECTED CHILDREN AND CONTROLS

\begin{tabular}{|c|c|c|c|}
\hline \multicolumn{2}{|c|}{ Condition of Umbilicus } & Affected Children & Controls \\
\hline $\begin{array}{l}\text { Healthy } \\
\text { Bleeding } \\
\text { Mird sepsis } \\
\text { Granuloma } \\
\text { Stumps }\end{array}$ & $\begin{array}{l}\cdots \\
\because \\
\cdots \\
\cdots\end{array}$ & 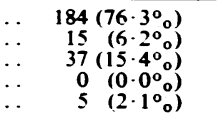 & $\begin{aligned} 364 & (77.9 \% \\
25 & (5.4 \%) \\
46 & (9.9 \% \\
30 & (6.4 \%) \\
2 & (0.4 \%)\end{aligned}$ \\
\hline & & $241\left(100_{0}^{\circ}\right)$ & $467(100 \%)$ \\
\hline
\end{tabular}

These figures suggest a greater tendency for a hernia to develop after mild sepsis. A significant fact is that no case of umbilical hernia occurred after granulation. A direct follow-up of a further 28 cases of umbilical granulation personally treated has revealed no example of herniation. It is presumed that the umbilical orifice becomes firmly closed by scar tissue.

\section{Size of the Umbilical Orifice}

Reutinely at the baby's first attendance at the clinic the size of the gap in the linea alba at the umbilicus was recorded. It was noted in many cases that the orifice through which the umbilical arteries and veins had passed into the cord appeared to be closed. One was, therefore, tempted to believe that a hernia would not develop. Sometimes there was a large gap, but such a gap did not always indicate a future hernia. It is interesting to note that in five neonates with a particularly large gap, sufficient to engage the little finger, no hernia subsequently developed, even though one infant had an attack of whooping cough. The possible anatomical explanation for this has been noted (vide supra). The incidence of gaps was recorded in the last 310 seen at the infant welfare clinic. (1) Quite a definite gap without a hernia was noted in 19 cases. None of these cases developed a hernia within the first six months of life. (2) A very slight pinpoint gap was noted in 50 cases, but none developed hernia. (3) The orifice appeared closed and there was no sign of an orifice to the examining finger in 167 cases and none of these developed hernia. (4) The orifice appeared closed as in (3) and yet a hernia developed later in seven cases. (5) A gap and a hernia were noted in 54 cases. (6) A granulation which required treatment was noted in 13 cases and thus a gap could not be palpated. (7) In three there was no gap but marked divarication of recti was noted. It is probable, therefore, that the palpable size of a gap in the linea alba at the umbilicus in early infancy is not an essential and determining factor as to whether a hernia will develop or not.

\section{Family History}

In 264 cases where a family history could be obtained 32 gave a definite history of a hernia in a brother, sister or parent. But many may have forgotten about a small hernia in another child. It is a common observation at the clinic that if one infant has a marked hernia frequently the next baby in the family has one also.

\section{Associated Inguinal Hernia}

Of these 283 cases, nine children had an inguinal hernia in addition to an umbilical hernia. Although it is known that both inguinal herniae and umbilical herniae have a higher incidence in premature babies only three of these nine cases were, in fact, premature babies. Two other cases of a umbilical hernia had the allied condition of hydrocoele of the hernial sac. Thus it was noted that 11 cases of inguinal hernia, all requiring operation, occurred in 283 cases of umbilical hernia, whereas in 213 controls in the year December, 1948, to December, 1949, there were only two cases of inguinal hernia.

\section{Associated Supra-Umbilical Herniae}

As suggested above, when firm fascial coverings of the abdominal wall at birth are not formed, both a weakness of the umbilical orifice and a weakness in the linea alba may result. A small supra-umbilical hernia may therefore co-exist with an umbilical hernia, and this was noted on seven occasions. In one of these cases the gap through which the umbilical hernia protruded was an indefinite oblong shape, possibly emphasizing the existence of weak fibrous tissue. It is possible for a supra-umbilical hernia to occur in the absence of true umbilical hernia and 
this was so of the only case mentioned in the birth records. These supra-umbilical herniae tend to be cured spontaneously in a similar manner to an umbilical hernia, presumably due to the development of the umbilical fascia in later infancy.

\section{Umbilical Hernia in Coloured Children}

There is a widespread opinion that umbilical hernia is an almost universal condition in coloured children. I have been interested to note, for example, that English fathers who have served abroad have remarked on the size of umbilical hernia in native children and in consequence have been unable to understand their wife's concern over the comparatively small size of the hernia in their own babies. The condition in coloured babies has been ascribed to malaria or other diseases causing a large liver or spleen. There have been four full negro babies at my infant welfare clinic in the last two years. One had a severe umbilical granulation and no hernia developed. The other three children developed hernia. Two cleared up in a few months but the other, which was the largest hernia seen in this series, ultimately reached operation (Fig. 4). These four were healthy babies born in England, and had no evidence of malaria.

Cullen (1916) considered the higher incidence among coloured babies to be due to a thicker cord and a larger umbilicus. Mori (1938) observed a seasonal occurrence of hernia corresponding approximately to the curve for craniotabes and rickets, i.e., the incidence being highest among babies born in January. This finding may, I think, have some relationship to respiratory infection. Jones (1941) was unconvinced that the high incidence of umbilical hernia in negro babies was related either

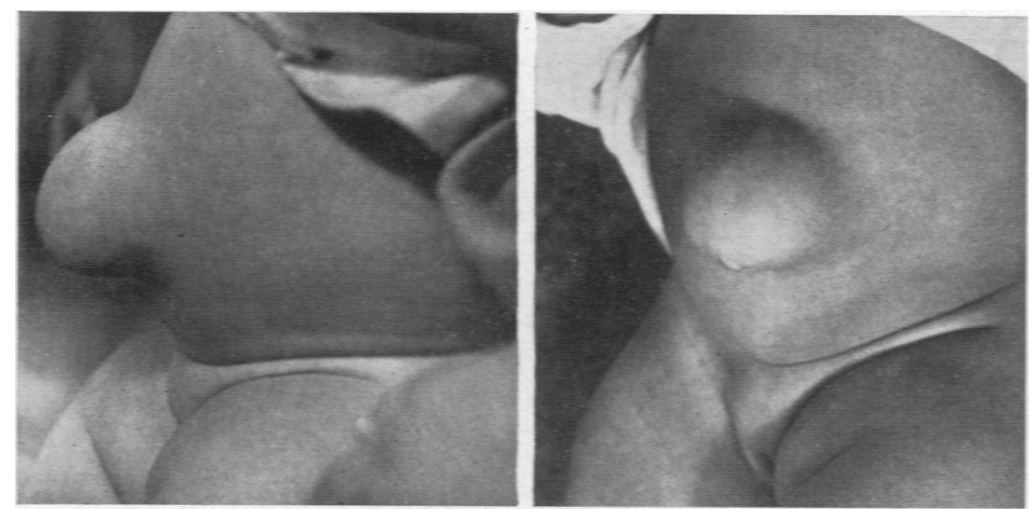

FK. 4.-A negro baby aged 14 months was first seen when the umbilical orifice was $3 \mathrm{~mm}$. in size and there was little umbilical protrusion. After five months continuous strapping the size of the umbilical orifice was $12 \mathrm{~mm}$. The umbilical area was continuously strapped until the condition was as shown above, she had no symptoms. to malnutrition, rickets or a large cord. Information received from Nigeria indicates that umbilical hernia is very common among babies there, but they nearly always disappear spontaneously and a senior medical officer states that he has never heard of a case of hernial strangulation. Probably the higher incidence in coloured babies represents an inherited trait.

\section{Immediate Causes for the Development of Umbilical Hernia}

The preceding observations give a picture of the possible inherent natal and post-natal factors that may influence the later development of an umbilical hernia. However, in many cases there appeared to be an immediate physical cause for the occurrence of the hernia, such as coughing, crying or vomiting.

Mothers frequently stated that the hernia was noted directly after the child's birth (Table 6). This appeared to be erroneous information, since in only one case was an umbilical hernia mentioned in the birth records and that particular hernia was, in fact, supra-umbilical. It would, therefore, be more accurate to regard these hernias as developing in the early weeks of life, possibly soon after the separation of the cord. The initial appearance of an infantile umbilical hernia after the age of 6 months is comparatively rare. Only one case was noted as late as $2 \frac{1}{2}$ years of age. Fig. 5 shows the time of the first appearance of the hernia in the out-patient and cases seen at the infant welfare clinic. The latter were seen personally and may be more accurate.

Though a hernia may develop in a healthy, fullterm, breast-fed baby, some immediate cause for the hernia was often apparent, as Table 7 shows.

Crying. Crying is often blamed by the mother as the cause of the hernia. In one case the parent gave a definite day and hour, and stated that the child cried all day and the hernia made its first appearance in the evening. Nine hospital cases appeared to be of this type and five of these had an associated inguinal hernia.

Coughing. In 16 hospital cases the hernia was reputed to have occurred during one particular attack of bronchial trouble. In a few of the clinic cases where the mother blamed a cough, a definite orifice had previously been felt in the linea alba, and it was considered 
TABLE 6

AGE OF FIRST APPEARANCE OF HERNIA

\begin{tabular}{ccc}
\hline Age (Months & $\begin{array}{c}\text { No. of } \\
\text { Hospital Cases }\end{array}$ & $\begin{array}{c}\text { No. of } \\
\text { Clinic Cases }\end{array}$ \\
\cline { 1 - 2 } $0-1$ & 54 & 13 \\
$1-2$ & 37 & 72 \\
$2-3$ & 6 & 29 \\
$3-4$ & 7 & 10 \\
$4-5$ & 2 & 1 \\
$5-6$ & 5 & \\
$6-7$ & 2 & 3 \\
$7-8$ & 1 & \\
$8-9$ & 9 & 1 \\
$9-12$ & 2 & \\
$12-15$ & 1 & \\
$15-18$ & 5 & \\
$18-21$ & 2 & \\
$21-24$ & 1 & \\
24 & &
\end{tabular}

- According to mother's history. + Personally seen.

TABLE 7

IMMEDIATE CAUSE FOR DEVELOPMENT OF HERNIA

\begin{tabular}{|c|c|c|}
\hline Cause & $\begin{array}{l}\text { No. of } \\
\text { Out-Patient Cases }\end{array}$ & $\begin{array}{l}\text { No. of Infant } \\
\text { Welfare Clinic Cases }\end{array}$ \\
\hline $\begin{array}{l}\text { Persistent crying } \\
\text { Cough } \quad . . \\
\text { Pertussis .. } \\
\text { Constipation } \\
\text { Flatulence } \\
\text { Marked vomiting } \\
\text { Bronchopneumonia } \\
\text { Gastro-enteritis }\end{array}$ & $\begin{array}{r}9 \\
18 \\
16 \\
3 \\
0 \\
1 \\
1 \\
1\end{array}$ & $\begin{array}{r}5 \\
20 \\
6 \\
0 \\
1 \\
1 \\
2 \\
1\end{array}$ \\
\hline
\end{tabular}

that a slight rise in intra-abdominal pressure would readily lead to umbilical protrusion. In a few cases the child had an attack of pneumonia or severe bronchiolitis in the first month of life and the hernia followed immediately after the illness. Fig. 5 emphasizes an increased tendency for a hernia to appear during the winter months.

Pertussis. This was a frequent cause. The severe cough and straining can be expected to raise the intra-abdominal pressure sufficiently to cause a hernia. Infective illness in a small child also lowers the muscle tone. In three cases a small hernia had been previously noted and had apparently undergone a clinical cure, but the attack of pertussis caused its reappearance.

Feeding Difficulties. Feading difficulties and intestinal disturbance appeared occasionally to be the cause of a hernia. Crying due to underfeeding and aerophagy was sometimes evident, and once there was a history of frequent vomiting. Constipation may be either a cause or a symptom of the umbilical hernia and in each of four cases the hernia persisted after 2 years of age. Possibly a general state of sub-nutrition and hypotonia were the cause both of the constipation and the hernia. Two infants had severe gastro-enteritis necessitating hospital treatment during the first few weeks of life, and a hernia was noted immediately afterwards.

Thus illness causing a rise in intra-abdominal pressure may initiate herniation through a baby's relatively insecure umbilical orifice, and an illness or infection, which lowers the general physique causing hypotonicity, may create a background favourable to the development of an umbilical hernia.

\section{Conditions Associated with Umbilical Hernia}

Certain definite conditions are associated with umbilical hernia.

Mongolism. Umbilical hernia is commonly present in mongolism, and it may be an associated sign related to the hypotonicity. Over a period of years about $\mathbf{5 0}$ mongols have come under my personal supervision and many, but not all, have had umbilical hernia. In each instance the hernia has disappeared spontaneously as in normal children. None required operation or persisted.

Cretinism. Similarly in cretinism an umbilical hernia is frequently seen and may again be related to severe hypotonia. Of 11 cretins personally seen, eight had had umbilical hernia. Six of these umbilical hernias had disappeared under thyroid treatment, and a case is shown in Fig. 6. Three cretins now over 7 years of age have never had an umbilical hernia.

Other Conditions. Umbilical hernia may be present in other conditions leading to a poor

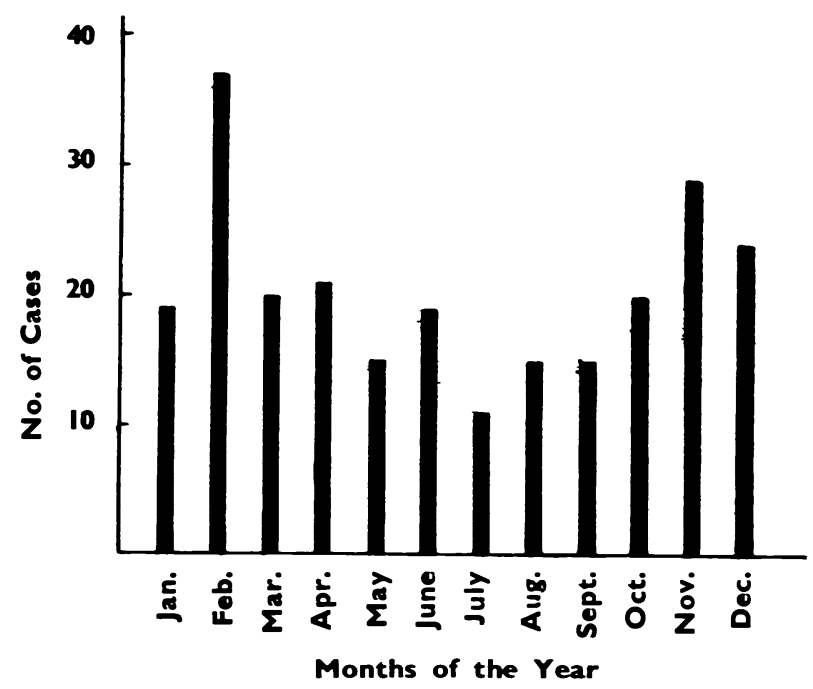

Fig. 5.- The month of year at which hernia first noticed in 225 cases where the parents" statement was known to be accurate. 


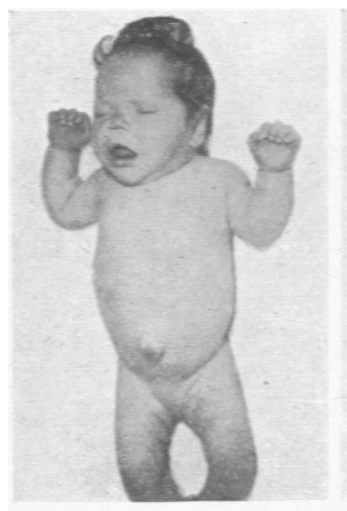

(a)

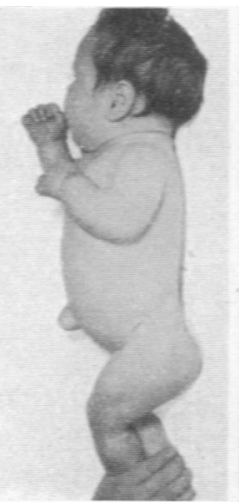

(b)

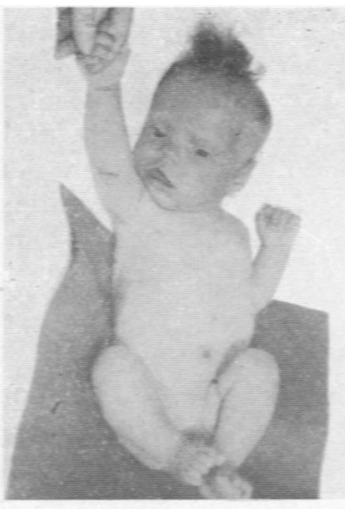

(c)

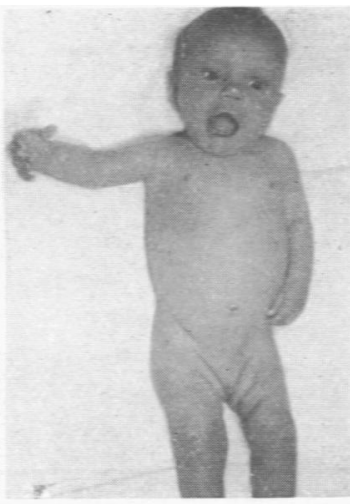

(d)

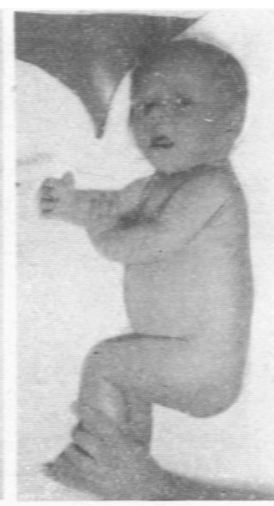

(e)

Fig. 6. - A cretin. shou ing how the umbilical condition cleared under thyroid treatment with no strapping.

physique and may be associated with congenital defects. Recently observed examples include umbilical hernia associated with congenital cataract, with congenital heart disease, with hypospadias, with spina bifida and myelomeningocoele and with gargoylism.

\section{Symptoms}

In this series of 283 cases of umbilical hernia there was no apparent disability in the baby. All observers were in agreement with the mothers that the hernia was causing no feeding difficulty, loss of weight, intestinal disturbance or pain. The children were in good health and full activity. Even the two very large hernias, one of which is shown in Fig. 4 gave rise to no symptoms.

Among 143 cases referred to hospital for consultant opinion symptoms were absent in all but five. Four of these mothers stated that the child complained of pain around the navel, but one mother thought it was due to constipation. One mother blamed a tiny hernia for severe vomiting and abdominal pain which occurred periodically, and this child was operated on without delay, but without relief of the symptoms. Henry (1941) states that severe abdominal catastrophe may cause pain apparently referred to a small umbilical hernia and so give the impression that the umbilical hernia is causing the symptoms. But in the few cases where the umbilical hernia was blamed for abdominal symptoms the cause was almost invariably elsewhere.

In one child aged $2 \frac{1}{2}$ years a protrusion appeared suddenly through the umbilical orifice four days before the first attendance at hospital. The protru- sion had caused pain and vomiting, and on examination there was a tender mass, presumably a small portion of omentum nipped in the orifice. Operation cleared the symptoms and signs. Anatomically this appeared to be of the so-called adult type of hernia in which the hernial protrusion was directed down the umbilical canal and may be an example of the 'semi-umbilical' hernia mentioned by Browne (1952).

No example of strangulation was seen in any of these 283 cases. There is no record of a case of strangulated infantile umbilical hernia in Bristol hospital records.

A child may play with and apply traction upon its own umbilical hernia, and if the hernia is markedly protuberant other children in the family may remark about it. Fig. 7 emphasizes this possibility. For this reason surgical treatment may be demanded by the parents.

\section{Treatment}

Careful consideration must be given to the treatment of a condition which is causing no symptoms and rarely gives rise to complications or future trouble. Strapping with adhesive plaster is frequently advocated but it is not without its disadvantages. If the umbilicus has not completely healed sepsis can occur under the strapping and an angry purulent condition of the umbilicus may be found. Two cases were seen. Impetigo develops in the damaged skin occasionally. The strapping is undoubtedly irritating to some babies and may be the cause of frequent crying. 


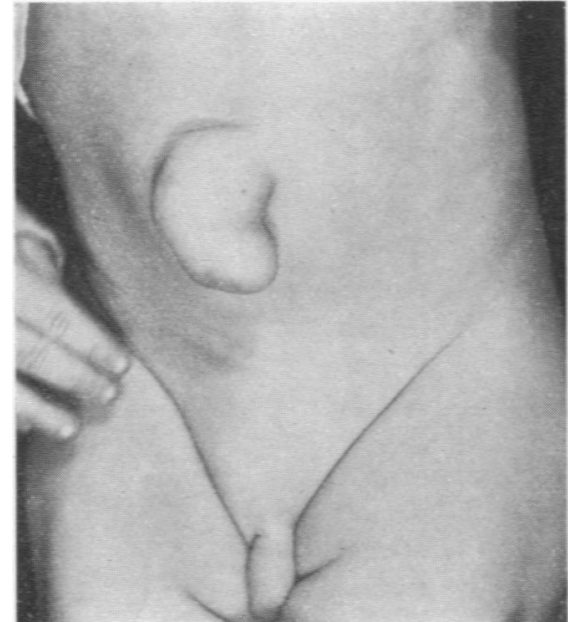

Fig. 7.-A.B., aged 11 months, a poor physical specimen, who had congenital absence of right external auditory meatus. Umbilicus was strapped from birth to 6 months of age. Defect in the linea alba was fairly small. Operated on at 11 months.

Trusses are designed to prevent the protrusion of the bowel into the hernial sac, supposedly by the pressure of an inflated rubber cushion.

On anatomical grounds these methods can hardly be defended. Forcible apposition to the two rectus muscles will not alter the actual size of the umbilical orifice and cannot accelerate a cure which is not already taking place naturally. Richet made this observation in 1856. It is highly important to note that a restriction on the normal activity of the abdominal muscles tends to cause loss of tone and a general ballooning of the abdominal wall. In fact, some children after a long period of strapping or the use of a truss have an anterior abdominal wall resembling in shape and tone the abdominal wall of a multipara (Fig. 8). Strapping may, therefore, have a very significantly deleterious effect. Trusses act in exactly the opposite way, the rubber cushion separating the internal edges of the rectus muscles and tending, contrary to common hypothesis, to enlarge the umbilical orifice and make an automatic cure less likely.

The common absence of symptoms or sequelae and the common finding of spontaneous cure even up to 5 or 6 years of age make the call for surgical treatment rather problematic. In some cases of longprotuberant hernia, with which the child can interfere and play, it may be justifiable to operate. The only cases of long-protuberant hernia in this series have been in children who had persistent umbilical strapping applied. I believe that if the condition was left and no strapping applied at any time this type of umbilical hernia in infants would not occur and certainly the child's attention would not be drawn to it.

For the past three years my policy has been to leave these umbilical hernias alone and wait for a spontaneous cure. A planned experiment to treat alternate cases with strapping and without strapping proved impossible to carry out. A mother whose baby was strapped finding another baby being cured spontaneously without strapping would soon

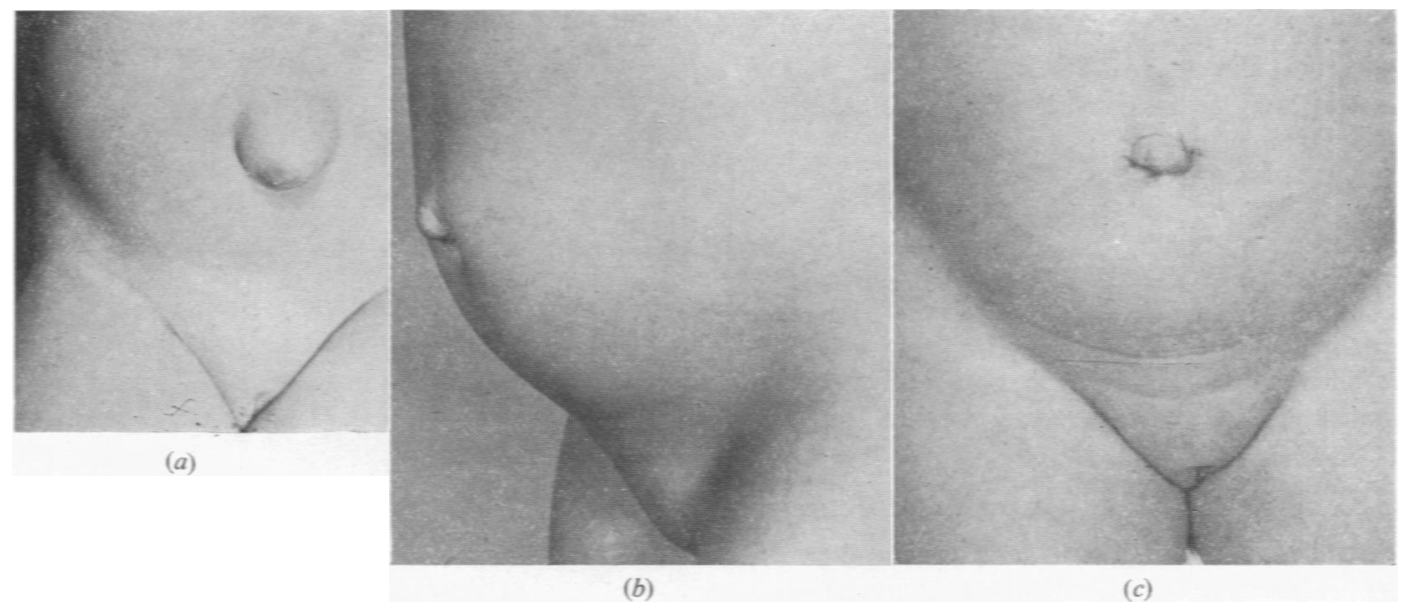

Fig. 8a.-A premature baby, breast fed, aged 11 months. This umbilical protrusion had been continuously strapped since 1 month of age. The hernia protrudes through the superior edge of the umbilical orifice. The condition improved after strapping was stopped.

FrG. 8b. - Child aged 3 vears. Hernia well on the way to automatic cure, and umbilical orifice now barely palpable. Abdominal muscles lax and flabby. No svmptoms. Baby brother had a large umbilical hernia, which was cured in seven months uith no strapping.

FK. 8 c.-Lateral and anterior view in a child aged 3 years. 


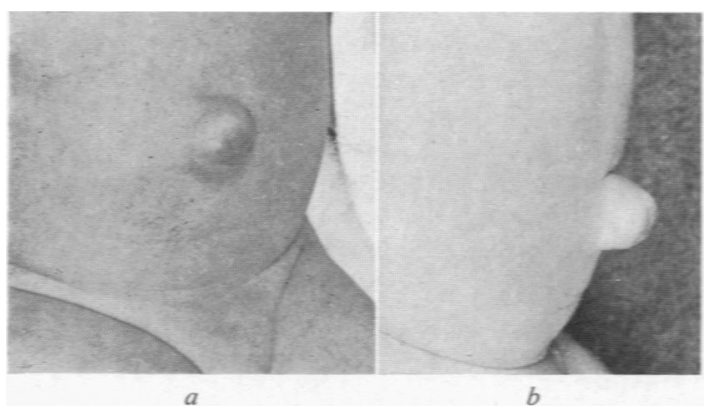

FiG. $9 a$ and $b$.- Healthy breast-fed baby aged 5 weeks with umbilical hernia.

remove the strapping. On the other hand, at the beginning of the investigation some mothers could not be persuaded not to apply strapping. In some cases strapping had to be discontinued because of the condition of the skin. For the last two years all members of my infant welfare clinics, health visitors, clinic nurses and mothers have been so convinced that strapping is not necessary that the method has been quite abandoned.

The last 122 umbilical hernias seen at the infant welfare clinic have not been treated in any way. All but three have made an automatic cure with complete absence of a peritoneal sac or pulsation on coughing. The three outstanding cases are well on the way to a natural cure.

Of the 132 cases of umbilical hernia over the age of 1 year sent for consultant opinion, 124 had been strapped for a considerable period-some as long as six years. Of the eight that had not been strapped, four became cured spontaneously while under observation. In the remaining four the hernia did not appear until the child was over a year old and may, based on anatomical considerations, have been the adult type of hernia.

In comparison with 122 untreated cases of umbilical hernia, 26 cases from infant welfare clinics were strapped for periods of one month or over. Fifteen of these 26 cases became cured automatically fairly quickly, but five spontaneously only after three and a half to six years. Three children aged between $3 \frac{1}{2}$ and 4 years have not yet become normal and three have received surgical treatment.

Possibly comparison should be made between severe and less severe cases to compare the effect of strapping. However, when first seen at the infant welfare clinic soon after birth, no case could be truly called severe. The gap in the orifice felt by pressure varied in size from about $2 \mathrm{~mm}$. to the size of the thumb. The size of the sac and the amount of protrusion were not proportional to the size of the orifice. There might be considerable protrusion

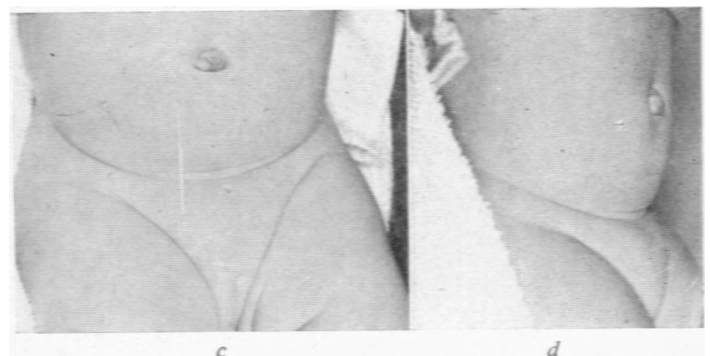

FIG. $9 c$ and $d$.- Same baby four months later, healthy, still breast fed. No treatment whatsoever was given for umbilical condition.

through a small orifice and very little protrusion through a large orifice. Forty-nine of the cases that were not strapped had a palpable umbilical orifice as large as the tip of a little finger and all became cured spontaneously. Two cases are illustrated in Figs. 9 and 10. Of 14 cases where the orifice was of similar size and which were strapped, five hernias have not completely disappeared in spite of the fact that the children have reached 3 years of age.

The negro baby with the very large umbilical hernia (Fig. 4) was initially seen at a few weeks of age and a record was made that the orifice was $3 \mathrm{~mm}$. in size and the protrusion was small. The baby was regularly strapped for a year and the size of the orifice and the hernia increased rapidly. Exactly similar events took place in the case of a large hernia in a white baby, who eventually required operation. None of the hernias that were not strapped reached any large proportions and this was also true of the hernias in the other two negro babies. The opportunity arose to strap one and leave one of two

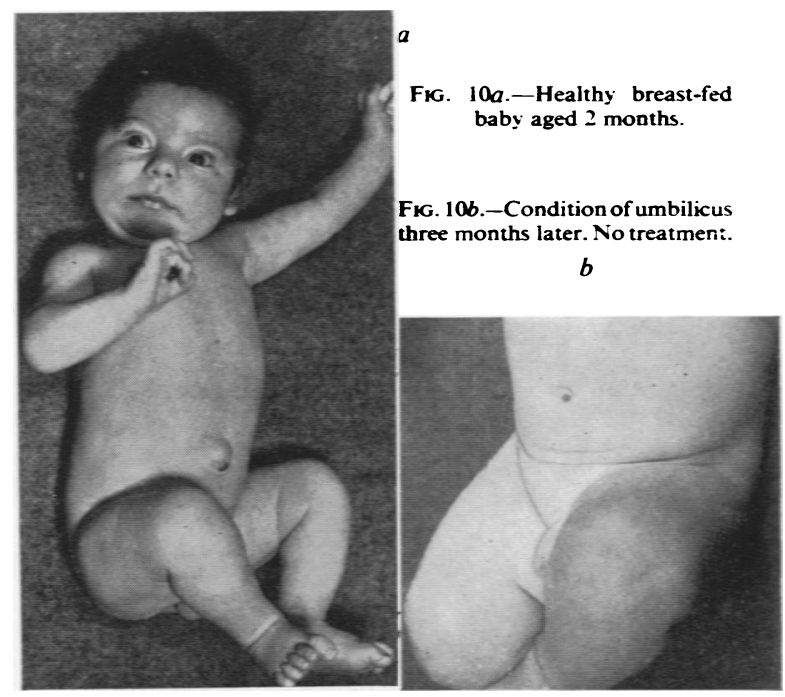




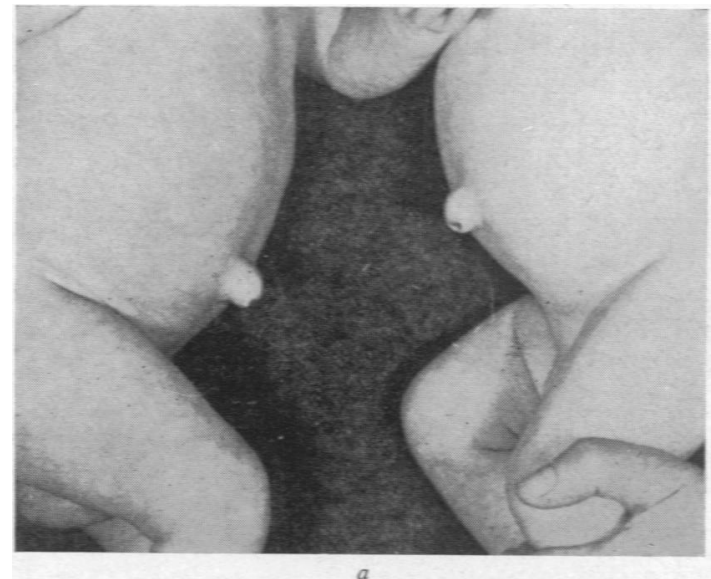

identical twins. This procedure could only be continued for about eight months as the child who was strapped developed impetigo in the area of strapping. It can be seen from the Fig. 11 that (although both children are of poor physical status) the child whose umbilical hernia was not strapped reveals more advanced healing.

In 17 cases from infant welfare clinics that had not cleared by one year of age, 10 had been strapped. Three of those children who had not been strapped had had a severe attack of pertussis which apparently only delayed the automatic cure. Three others who came from poor homes had had several attacks of bronchitis, but despite this, and in the absence of treatment for the hernia, a natural cure is proceeding. One healthy little boy made a perfectly satisfactory cure by $\mathbf{2 0}$ months. The clinical emphasis is strongly against strapping.

In many cases where the parents expressed a desire for operation the baby's name was placed on the waiting list. Owing to shortage of beds there was frequently an interval of several months before the baby was admitted to hospital and in this interval, and in the absence of any form of treatment, spontaneous cure had frequently occurred. During the course of these investigations long-term observations were made on a series of nine cases. Four cases were followed up and found to be cured by 5 years of age, two were cured by 6 years, two by 7 years and one by 8 years of age.

\section{Incidence}

As already mentioned, the incidence among 573 healthy babies seen at infant welfare clinics was $1: 5 \cdot 4$. The high incidence of umbilical hernia in infants might suggest that nature would design a cure.

An opportunity arose to note the incidence in nursery school children. Ten very small herniae, all

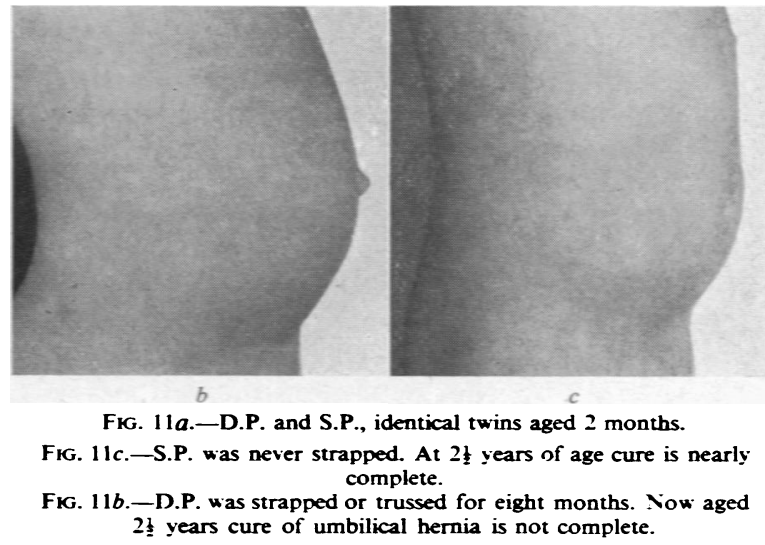

in children aged 2 years, were found among 105 children in one school. All had cleared before the children left school at 5 years. This relatively high incidence may have been related to the practice of recruiting children for nursery schools from homes where maternal care and circumstances are unfavourable. The healthier life in a nursery markedly improved the muscular tone of these children and may have been responsible for an accelerated cure. In another nursery school, among $\mathbf{3 0 0}$ children aged between 3 and 5 years no hernia was found.

Among 250 school children aged 5 to 11 years personally examined, five hernias only were noted. Four were very small and one was large and this had been strapped for six years. Two half-caste children had been operated on for umbilical hernia in infancy. In another survey of approximately 3,000 school children aged between 5 and 18 years only three umbilical hernias were found, and one of these became cured spontaneously in the following few months. These very few hernias in older children were causing no morbidity. Routine examination of 800 university students showed no evidence of umbilical hernia. This suggests that the ultimate residuum of infantile umbilical weakness or abnormality in the population is negligible.

\section{Discussion}

From the evidence available in this investigation and from consideration of the anatomy, it would appear that a patent orifice at the umbilicus is present for some time after birth and can be regarded as normal. The size of the orifice may vary from a minimum of $1 \mathrm{~mm}$. to the dimensions of an adult thumb. The observation that the fascial strengthening of the umbilical region has not fully developed in the early months of life offers a simple explanation for the occurrence of a small hernia through the umbilical orifice even in a perfectly healthy infant. 
The anatomical state can be regarded as no more than a variation within the normal.

The occurrence of an umbilical hernia in a particular infant might be related to difference in embryological, anatomical and inherited make-up, and with the normal growth of the baby the umbilical fascia develops to an extent which will bring about the spontaneous disappearance of the hernia.

Conditions which contribute to under-development or late maturation of the fascia of the abdominal wall, or a particular weakness of this fascia, or a marked hypotonicity of the abdominal muscles, will increase the incidence of umbilical hernia, or aggravate the condition when present and delay a spontaneous cure. Thus deficiency in the local fascia is particularly demonstrable in premature infants and in these children umbilical herniae occur with greater frequency. Umbilical sepsis has been observed as a contributory factor in the development of hernia. In upper respiratory infection or any general infection umbilical hernia is more likely to develop or to show delay in natural cure. Conditions such as mongolism and cretinism are classically related to umbilical hernia and indicate that umbilical hernia is more likely to appear in disease of which muscular hypotonicity is characteristic.

From the observations recorded in this paper there appears to be little doubt that in the healthy baby umbilical hernia has a very strong potentiality for spontaneous disappearance. In the present survey $93 \%$ of children became cured automatically in the first year of life in the absence of any strapping or truss. There is considerable evidence that the local application of restrictive appliances may actually delay the disappearance of the hernia or even increase its severity, perhaps because the limitation of spontaneous and free movements of the abdominal musculature inhibits stimulus to local anatomical maturation.

\section{Conclusions}

Two hundred and eighty-three infants with umbilical hernia have been studied. In this series a frequency of an umbilical hernia of one in six infants has been recorded. The first appearance of the hernia is usually within the first few months of life and rarely after six months.

The incidence of herniation after premature or twin births is significantly higher than after a normal birth.

Breech births, babies of high birth weight and babies whose cords are of unusual length appear somewhat more predisposed to umbilical hernia. Mild sepsis of the umbilicus after separation of the cord is related to an increased tendency to herniation.

Granulation tissue forming at the umbilicus prevents herniation.
Umbilical hernia is compatible with normal healthy growth and its occurrence is, in part, dependent on the child's inherited status. Constitutional conditions causing either hypotonicity of the abdominal musculature or a rise in the intraabdominal pressure favour the development of a hernia and aggravate the condition if present.

In infants symptoms directly attributable to umbilical hernia are rare and no case of strangulation has been recorded.

Spontaneous cure is a very common event. The use of restrictive appliances such as strapping and trusses frequently aggravate the condition and delay a spontaneous cure.

The ultimate incidence in school children and early adult life is very small.

In a prolonged investigation of this type. I have received help from many sources. I would particularly wish to thank Professor A. V. Neale, at whose suggestion this investigation was carried out, for detailed assistance in the preparation of this paper, and Mr. W. A. Jackman, who allowed me to obtain the details from his outpatient cases over a period of years and Professor R. $\mathbf{H}$. Parry for permission to use the facilities of the infant welfare clinics. My thanks are also due to Dr. G. Herdan for statistical help, to Dr. A. A. Craig and Dr. S. W. Terry for obtaining the figures from school children and Dr. D. E. Oliff for the figures from university students. I wish to thank the general practitioners who allowed me to pay domiciliary visits to their patients and the health visitors who gave full and willing cooperation.

BIBLFGRAPHY

Apley, J. (1948). Postgrad. med. J., 24, 588

Barrington-Ward, L. (1947). Prastitioner. 159. 376

Beadnell, L. M. M. (1942). Brit. med.J., 1, 565

Bellei, A. (1936). Lattante, 7, 359.

Bennett-Jones, M. J. (1944). Brit. med. J., 1. 78.

Browne, D. (1952). Ibid., 2. 1144.

Chamberlain, J. W. (1936). J. Pediat., 9, 215

Cohen, R. (1948). Amer. J. Dis. Child.. 76, 44.

Cullen. T. S. (1916). The C'mbilicus and its Diseases. Philadelnnia.

Erichsen, J. E. (1884). The Science and Art of Surgery, 8th ed.. vol. 2. pp. 822-823. London.

Fèvre, M. and Barcat, J. R. (1947). Presse med., 54, 500

Fraser, J. (1926). Surgery of Childhood, Vol. 2, pp. 774-776. London.

Frazer, J. E. (1931). A Manual of Embryology. London.

Freshman. E. (1933). Lancet, 2. 701

Friedjung. J. K. (1935). Arch. Kinderheilk.. 104. 168.

Gorelow. M. A. (1934). Arch. klin. Chir., 181, 395

Gvllenswärd, C. (1937). Acta paediat. Lppsala, 20. 237

Hamilton, $\mathbf{W}$ J. Boyd J D and Mossman, H. W. (1952). Human Embryology, p. 368 . Cambridge.

Henry, A. K. (1941). St. Bart's Hosp. Rep.. 2. 234

Heiffeld, G. (1938). Amer. J. Surg., 39, 422.

Jones, J. W. (1941). Arch. Pediat.. 58. 294.

Kuntzmann, J. (1947). Pediatrie, 36, 307.

Magnus, P. Von (1942? Vord. med. (Hospitalstid). 13.930.

Mahorner, H. (1940). Ann. Surg., 111. 979.

Mori, S. (1938). Orient. J. Dis. Infants, 24, 10.

Moschcowitz. A. V. (1915). Ann. Surg., 61, 570.

O'Leary, C. M. and Clymer, C. E. (1941). Amer. J. Surg., 52. 三s

Parsons, H. H. (1940). Milit. Surg.. 87, 298.

Reilly. W. A. (1941), J. clin. Endocr., 1. 532 .

Richet, A. (1856). Arch. gen. Med., ser. 5, 8, 641

(1857) Ibid Ser. 5.9 .59$.

Spivack. M. (1946). Amer. J. Obst. Gınec. 52. 387

Spivack. M. (1946). Amer. Obst. Ginec.. 52. 387.

Stil, G. F. (1931). The Furut (1939). Fukuoka Acta med.. (Autoref. Sect.). 32. 115

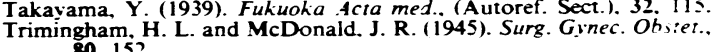
80,152 .

Widal de Cassis, A. T. (1848). Des hernies ombicales et épigastriques. Paris.

Woods, G. E. (1952). Brit. med. J., 2. 1148

Wvburn, G. M. (1939). J. Anat., 73. 289. 